\title{
Prosthodontic Rehabilitation of a Cleft Patient with Andrews Bridge: A Case Report
}

\section{Rachana Chaudhary*, Dinesh Kumar, Amit Khattak, R K Yadav, Anup Gopi and Dhruv Sharma}

Department of Prosthodontics and Crown and Bridge, Army Dental Centre, Research and Referral, Delhi, India

*Corresponding author: Rachana Chaudhary, PG Resident, Department of Prosthodontics and Crown and Bridge, Army Dental Centre, Research and Referral, Delhi Cantt-110010, Delhi, India, Tel: 917023283220

\begin{abstract}
Complete aesthetic surgical replacement of the lost tissues is difficult and unpredictable, particularly when a greater degree of the residual ridge has been lost due to trauma, congenital defects or other pathologic process. When treating cleft-palate patients with congenital or acquired defects, the Andrews bridge permits rehabilitation with a fixed-removable partial denture when conventional methods are contraindicated. This system permits the replacement of the lost teeth as well as supportive structures necessary for proper aesthetics. It provides access to an oral-nasal fistula when one is present. This case report describes successful treatment of a cleft-palate patient with the use of the Andrews bridge. Andrews bridge system is composed of two components: Fixed component (retainers on abutments joined by bar) and a removable component.
\end{abstract}

\section{Keywords}

Fixed, Removable, Partial, Esthetics, Andrews, Cleft palate

\section{Introduction}

Among various treatments for the patient with compromised edentulous space is the fixed removable partial denture. Mainly indicated in patients whose residual ridge has a relationship to the opposing dentition that would prohibit the aesthetic placement of the pontics of a fixed partial denture and patients who have extensive alveolar bone and tissue loss. Patients with a unilateral or bilateral cleft palate with missing anterior teeth, and a deficient alveolar ridge presents the problem of restoring the missing teeth and the alveolar ridge. McCracken stated that when anterior teeth are replaced with a removable partial denture, support for the anterior segment is difficult to obtain unless multiple rests on several adjacent teeth are utilized. It is better to avoid the numerous components by using anterior fixed partial dentures [1]. Conventional fixed partial denture and implant supported FPD fails to replace the lost soft tissue structures. In such cases replacement of teeth along with the supporting structures can be achieved by Andrew's Bridge [2].

In Andrews bridge system abutment tooth stabilization is combined with a removable partial denture. This technique, with some technical variations, possesses the advantages and complexity of fixed removable restorations. The principal advantage is the flexibility in placing denture teeth. The physiologic advantages are effective oral hygiene and increased stability of the splinted teeth. The location of the bar near the gingival margin and the decreased mobility of the splinted teeth support two principles of physics in increasing the stability of the abutments [3].

The purpose of this article is to present a case of cleft patient rehabilitated with the Andrews Bridge System. This prosthesis is designed to meet the requirements for aesthetics, comfort, phonetics, hygiene, and favourable stress distribution to the abutments and soft tissue.

\section{Material and Methods}

A 25-year-old male patient reported to the depart-

Citation: Chaudhary R, Kumar D, Khattak A, Yadav RK, Gopi A, et al. (2020) Prosthodontic Rehabilitation of a Cleft Patient with Andrews Bridge: A Case Report. Int J Oral Dent Health 6:107. doi. org/10.23937/2469-5734/1510107

Accepted: February 17, 2020: Published: February 19, 2020

Copyright: (C) 2020 Chaudhary R, et al. This is an open-access article distributed under the terms of the Creative Commons Attribution License, which permits unrestricted use, distribution, and reproduction in any medium, provided the original author and source are credited. 
ment of prosthodontics with chief complaint of missing upper front teeth. His history and clinical examination revealed that he was operated for cleft lip and palate. The appropriate bar was selected from the preformed curvatures available using a diagnostic cast. The bar followed the residual ridge and was positioned in the approximate centre of the abutments. Clinical examination revealed seibert's class three ridge defect on left maxillary anterior region. Patient had missing 21, 22, 23, 24 (Figure 1).

\section{Procedure}

1. Patient was educated and motivated for the replacement of missing teeth. Implants supported prosthesis was not possible because of insufficient bone. Complete oral prophylaxis was carried out.

2. Diagnostic impressions were made with irreversible hydrocolloid and impressions were poured in type 3 dental stone. Diagnostic casts were mounted on three pin articulator and in maximum intercuspation using interocclusal record (Figure 2 and Figure 3 ).

3. Treatment plan was formulated and it was decided to rehabilitate the patient with fixed removable An-

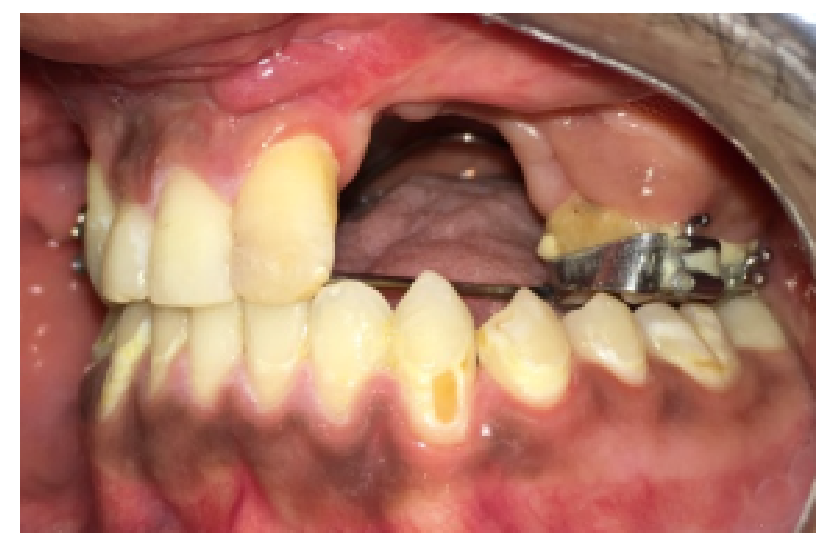

Figure 1: Missing 21, 22, 23, 24 with sieberts class 3 defects.

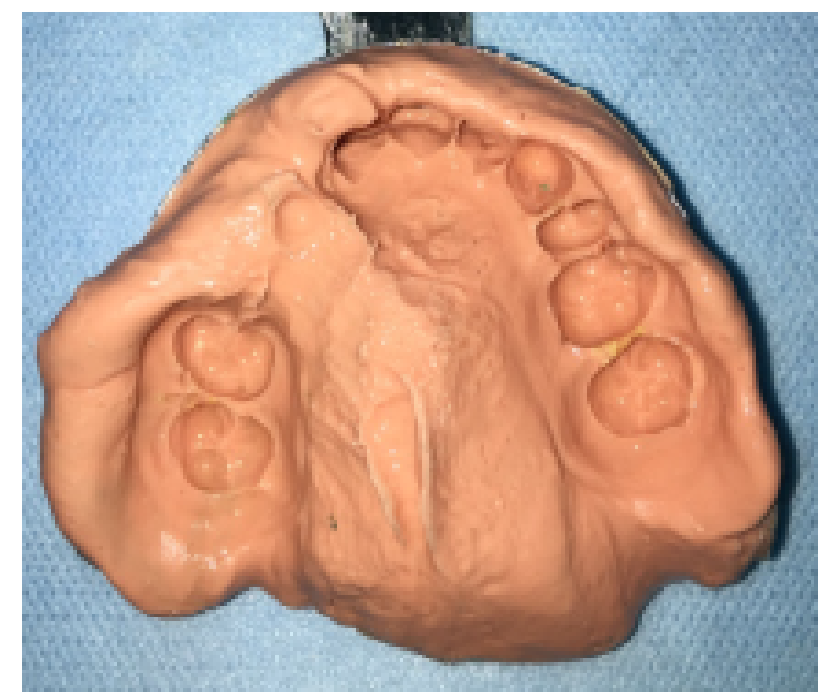

Figure 2: Diagnostic impression. drews bridge prosthesis.

4. Tooth preparation was done irt 11,12 and 26 to receive PFM crowns that will be connected with bar attachment gingival retraction was done using chemico-mechanical method and final impression was made with two stage putty wash technique using polyvinyl siloxane impression material (Figure 4 and Figure 5).

5. Provisionalisation was done on 11,12 and 26 using tooth colored acrylic using indirect technique and impression were made with irreversible hydrocolloid impression material. Acrylic interim partial denture was inserted (Figure 6).

6. Master cast was prepared using type 4 dental stone.

7. Wax up was done on 11,12 and 26 for pfm crown and was connected using prefabricated plastic bars. Bar was placed parallel to the ridge taking care to place it provide adequate space for the removable component of the prosthesis. Casting was done.

8. After finishing and polishing framework was tried firstly on the master cast then intraorally (Figure 7).

9. Shade selection was done under adequate lighting

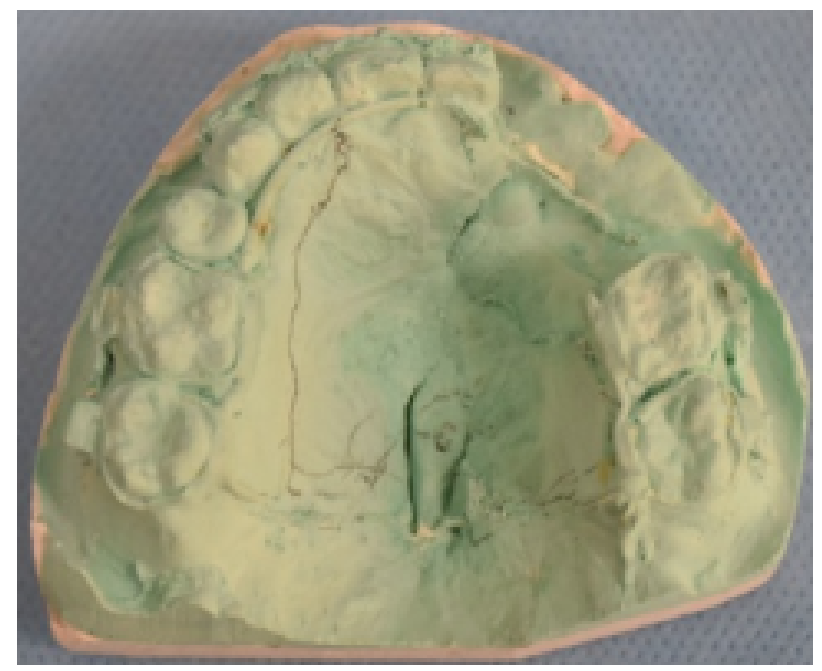

Figure 3: Diagnostic cast.

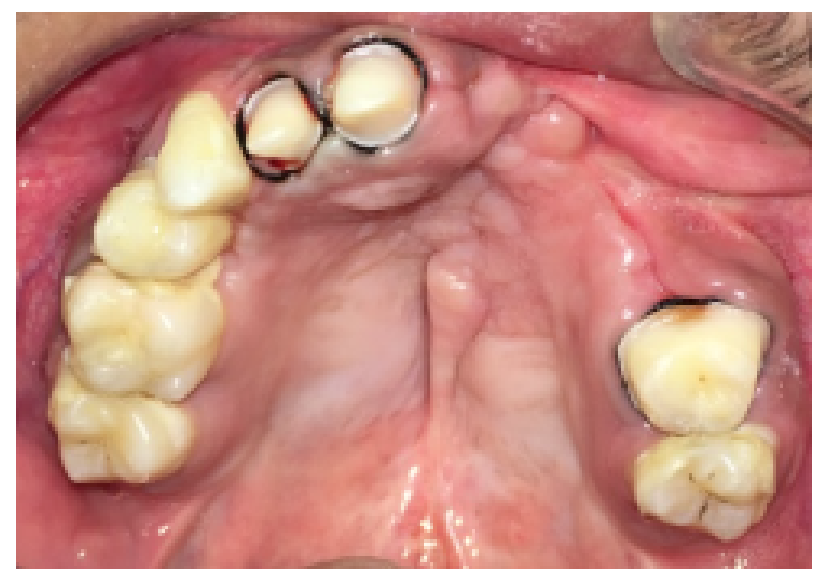

Figure 4: Tooth preparation irt 11, 12, 26. 


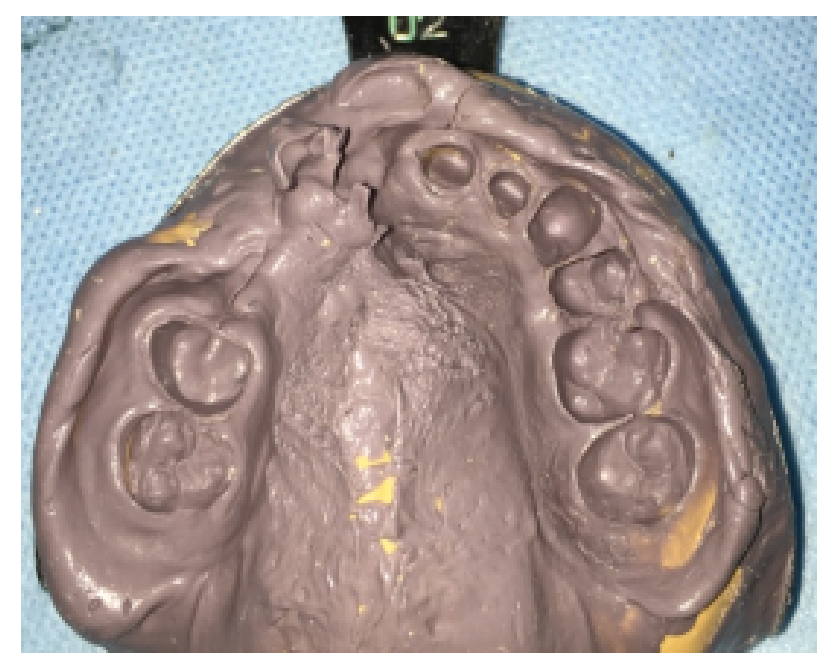

Figure 5: Polyvinyl siloxane impression.

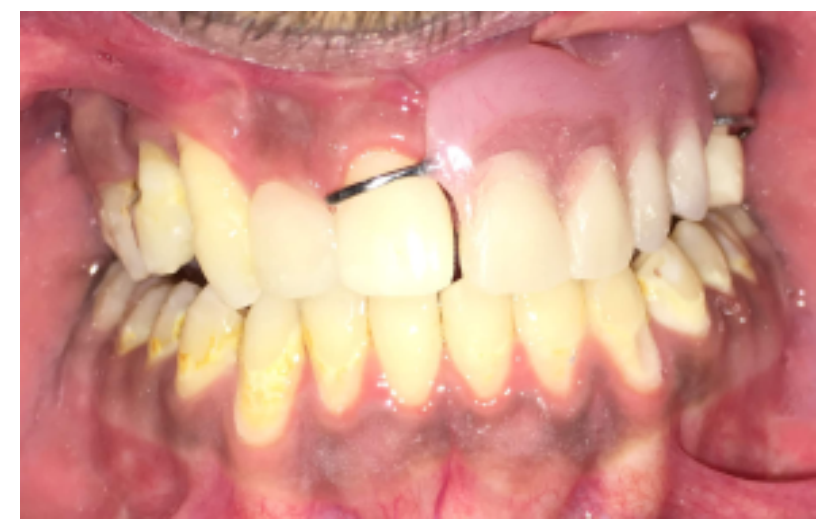

Figure 6: Provisionalisation.

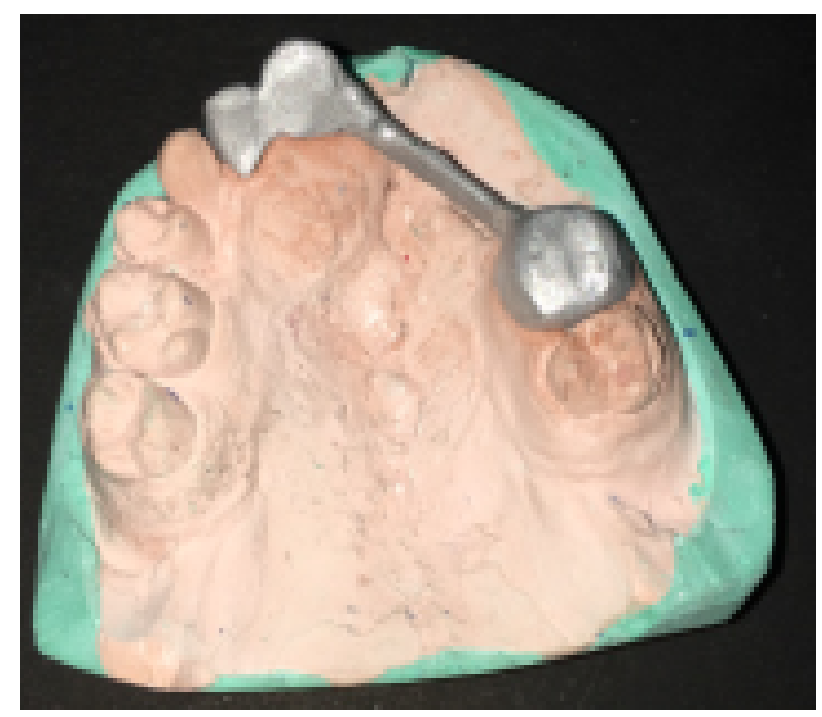

Figure 7: Metal framework try in on cast.

and ceramic layering was done.

10.After bisque try in prosthesis was cemented using glass ionomer luting cement (Figure 8).

11.Impression was again made using irreversible hydrocolloid after blocking out the undersurface of the bar and poured with type 4 dental stone for fabrication

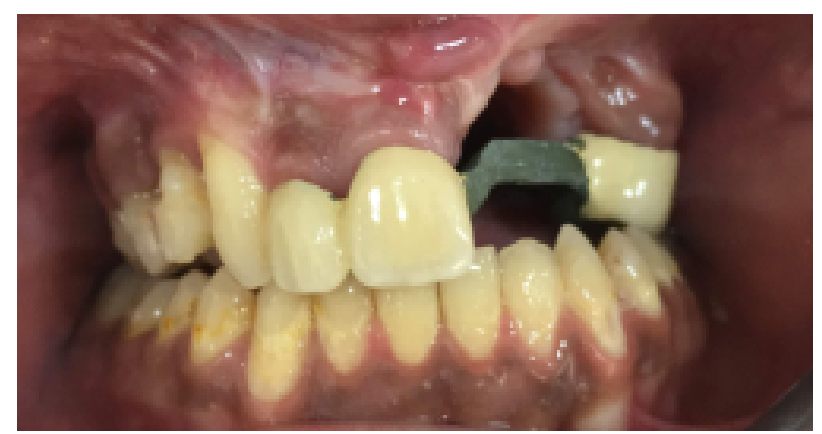

Figure 8: Framework placed in situ.

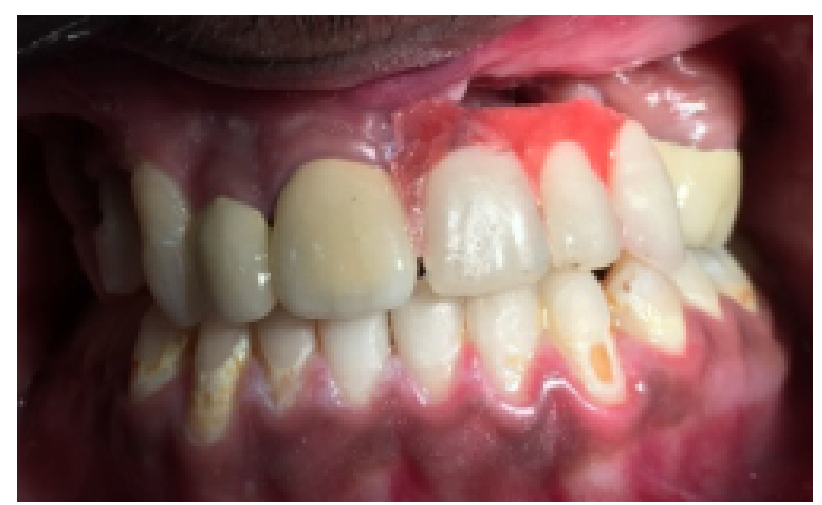

Figure 9: Teeth arrangements try in.

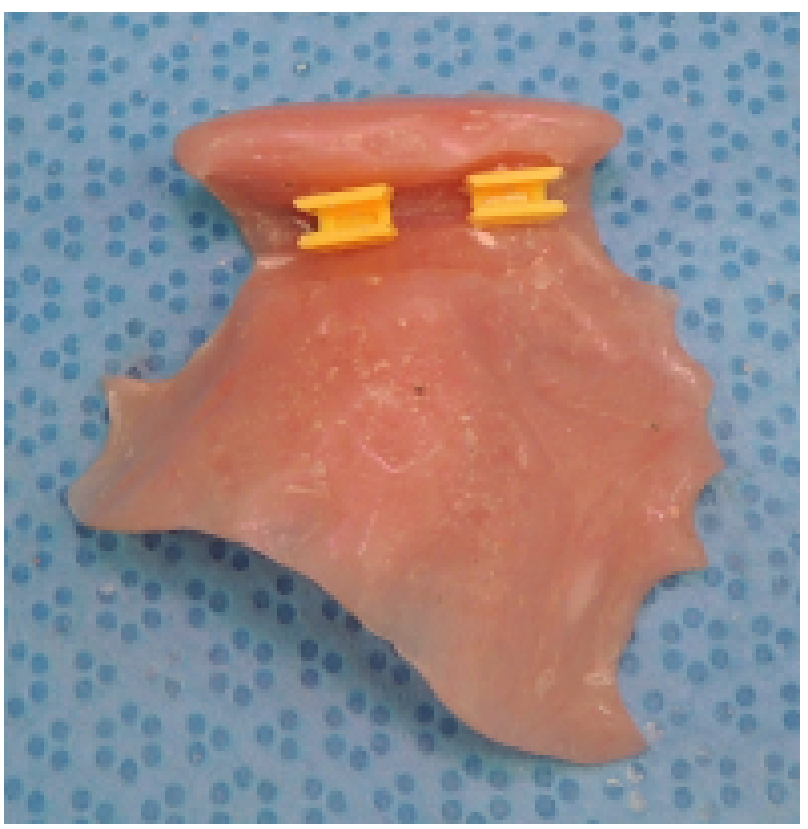

Figure 10: Clips picked up on rpd.

of superstructure.

12. Casts were mounted on articulator and teeth arrangement was done and try in was done (Figure 9).

13.Acrylisation was done. Undersurface of the bar was again blocked and clips were attached to the bar and picked up with autopolymerising PMMA into the removable superstructure (Figure 10, Figure 11 and Figure 12). 


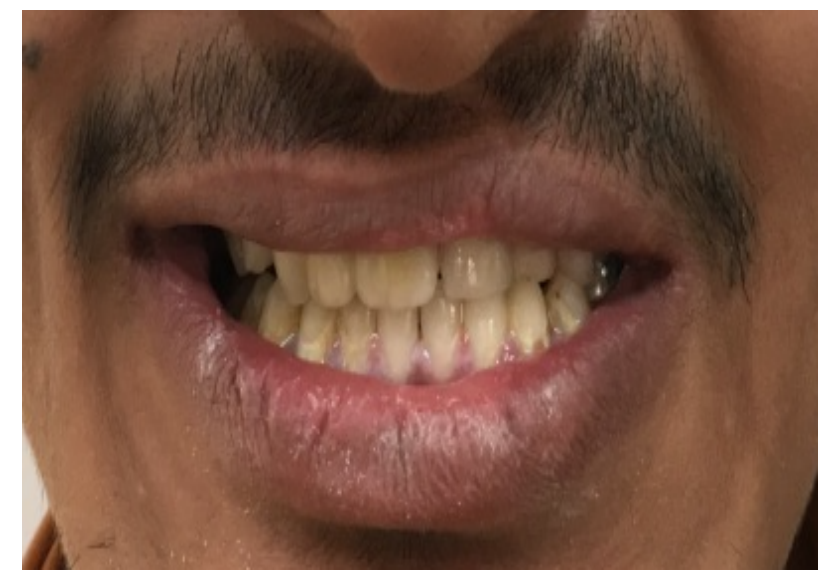

Figure 11: Prosthesis in situ.

14.Patient was given instructions regarding insertion and removal of the prosthesis. Patient was motivated for cleaning and maintenance of the prosthesis. Patient was on regular follow up.

\section{Result}

Rehabilitating this patient was challenging considering large ridge defect and high cosmetic index. Patient was satisfied with the aesthetics of the prosthesis. Along with replacement of missing teeth, the removable component of the Andrews bridge gave the lip extra support and overall improved the appearance and confidence of the patient.

\section{Discussion}

Most commonly encountered congenital anomalies include CLP accounting to approximately one in 800 live births [4]. The incidence of congenitally missing teeth, especially lateral incisors adjacent to the alveolar cleft is high [5]. Quality and quantity of existing contiguous hard and soft tissues, systemic conditions, and economic status of the patient play a significant role in treatment planning, clinical outcome, and prognosis. The most commonly seen defects are the combined Class III defects (56\% of cases), followed by horizontal defects Class I (33\% of the cases) [6].

Vertical defects were reported to be found in $3 \%$ of the patients [7]. Large vertical and horizontal bone defects pose a prosthodontic challenge as it is difficult to restore aesthetics and function. Such clinical conditions are not successfully treated by conventional fixed or removable prosthesis. In cleft lip and palate patients have generally Seibert's class III ridge defect with inadequate height and width [8]. When there is a limitation of bone grafting/surgical augmentation, alternative treatment modalities should be considered. Conventional fixed partial denture treatment was not a treatment of choice for the patient due to the exaggerated movement of the labial mucous membrane fold during function. This would continuously exert pressure on the fixed partial denture and deleterious effect on the abutments. Hence, Andrew's bridge is an alternative choice

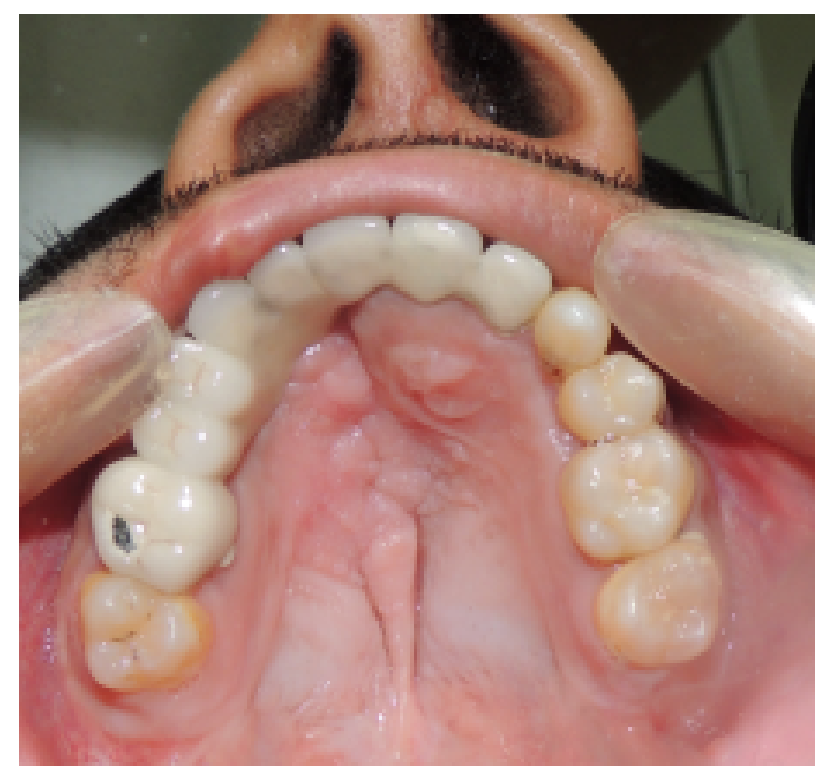

Figure 12: Intraoral post-op photograph.

of treatment.

The Andrew's bridge system is composed of two components: Fixed component (retainers on abutments joined by bar) and removable component [5]. Dr. James Andrews of Amite Louisiana (Institute of Cosmetic Dentistry, Amite, LA, USA) first introduced a fixed removable prosthesis [9]. The removable partial denture was not a choice of treatment since placement of clasps in the aesthetic zone is not desirable for a young patient [10]. Since the abutments are strong enough to receive load, a fixed-removable partial denture in these situations offers both function and aesthetics. When a proper diagnosis and treatment plan is made Andrew's bridge provides a better treatment. Replacement along with an acrylic denture flange for tissue defects is an added advantage as it does not require special prosthesis for the gingiva as in fixed dental prosthesis. Since the prosthesis is retained by a bar retainer, the taste perception is unaltered as the flanges need not be extended palatally for support. The acrylic prosthesis can be removed by the patient when desired for hygienic access [11].

In this case, the support mechanism is shared by the tooth, and the tissues to some extent and the bar serves as a retentive and stabilizing tool for the removable segment. Immeleus JE and Aramany $M$ described use of fixed-removable partial denture for cleft palate patients. The Andrew's bridge permits rehabilitation in cleft- palate patients with congenital or acquired defects when conventional methods are contraindicated. It permits the replacement of the lost teeth and supportive structures [12].

There are few disadvantages with Andrews bridge system like wearing away of the plastic clip which needs replacement form time to time, there are additional lab steps and needs meticulous planning 
during the placement of the bar to prevent tissue impingement and also provide adequate relief between the metal bar and the tissues to allow proper oral hygiene maintenance by the patient. This fixed removable prosthesis can be used for short edentulous span, if used for long spans, there will be increased flexure of the metal bar and will lead to failure of the prosthesis [13].

\section{Conclusion}

Andrews Bridge system is a fixed-removable prosthesis that is indicated in patients with few missing teeth and large localized ridge defects. This case report describes prosthodontic rehabilitation of a young patient with cleft lip and palate with Andrews bridge replacing missing teeth with the prosthesis patients there was marked improvement in patients appearance, speech and confidence.

\section{Financial Support and Sponsorship}

Nil.

\section{Conflicts of Interest}

There are no conflicts of interest.

\section{Patient Consent}

Obtained.

\section{References}

1. William L McCracken (1965) Partial denture construction. ( $2^{\text {nd }}$ edn), The CV Mosby Company, St. Louis.

2. Van den Bergh JP, Ten Bruggenkate CM, Tuinzing DB (1998) Preimplant surgery of bony tissues. J Pros Dent 80: 175-183.
3. Robert J Everhart, Edmund Cavazos Jr (1983) Evaluation of a fixed removable partial denture: Andrews bridge system. J Pros Dent 50: 180-184.

4. Hickey AJ, Salter M (2006) Prosthodontic and psychological factors in treating patients with congenital and craniofacial defects. J Prosthet Dent 95: 392-396.

5. Ozlem A, Burcak K, Muhammet S, Bulem Y (2013) Prosthodontic rehabilitation of cleft lip and palate patients with conventional methods: A case series. Int J Prosthodont Restor Dent 3: 120-124.

6. Rathee M, Sikka N, Jindal S, Kaushik A (2015) Prosthetic rehabilitation of severe Siebert's Class III defect with modified Andrews bridge system. Contemp Clin Dent 6: 114116.

7. Prasan KK, Joshi S, Shalini BN, Sowjanya K, Jessudass G (2014) Achieving esthetics with Andrews bridge. Int J Prosthodont Restor Dent 4: 127-130.

8. Muthuvignesh J, Bhuminathan S, Egammai S, Narayana RD (2013) Improving facial esthetics with Andrews' bridge: A clinical report. Int J Multidiscip Dent 4: 884-887.

9. DeBoer J (1993) Edentulous implants: Overdenture versus fixed. J Prosthet Dent 69: 386-390.

10. Finley JM (1998) Restoring the edentulous maxilla using an implant-supported, matrix-assisted secondary casting. J Prosthodont 7: 35-39.

11. Cura C, Saraçoglu A, Cötert HS (2002) Alternative method for connecting a removable gingival extension and fixed partial denture: A clinical report. J Prosthet Dent 88: 1-3.

12. Immeleus JE, Aramany M (1975) A fixed-removable partial denture for cleft palate patients. J Prosthet Dent 34: 286291.

13. Cheatham JL, Newland JR, Radentz WH, O'Brien R (1984) The 'fixed' removable partial denture: Report of case. J Am Dent Assoc 109: 57-59. 